\title{
Knowledge of Human Papillomavirus and Uptake of its Vaccine among Female Undergraduate Students of Ambrose Alli University, Ekpoma, Nigeria
}

Isara $A R$, Osayi $N$

Department of Community Health, School of Medicine, University of Benin, Benin City, Nigeria

Keywords
Cervical
cancer;
Human
Papillomavirus;
HPV vaccine;
Undergraduate
students;
Nigeria

\section{ABSTRACT}

Background: Human Papillomavirus (HPV) is a prerequisite for the development of cervical cancer which is the fourth most common cancer affecting women worldwide. The use of HPV vaccine has been found to be responsible for significant decline in the prevalence of HPV infection and consequently, of cervical cancer. This study assessed the knowledge of HPV and the uptake of HPV vaccine among female undergraduate students of Ambrose Alli University, Ekpoma, Nigeria.

Methods: This institution-based cross-sectional study was carried out among 229 students selected using multi-staged sampling technique. A structured, pretested, selfadministered questionnaire was used to collect data. IBM SPSS version 21.0 was used for data analysis. Statistical significance was set at $p$-value less than 0.05 .

Results: Only $12(5.2 \%)$ students were knowledgeable about HPV and 39 (17.0\%) were aware of the existence of HPV vaccines. The participants' age $(p=0.031)$ and level of study $(p=0.026)$ were significantly associated with knowledge of HPV. Only $1(0.44 \%)$ student had received the vaccine. Eight (10.8\%) students had their sexual debut at 10 to 14 years, $9(12.1 \%)$ had more than five sexual partners and $21(23.4 \%)$ never used condom during sexual intercourse.

Conclusion: The knowledge about HPV infection and uptake of HPV vaccine were very low in this study. Concerted effort should be made by health authorities to create awareness about HPV infection and its vaccine among university students. This will improve HPV vaccine uptake, prevent HPV infections and reduce the prevalence of cervical cancer.

\section{INTRODUCTION}

Human papillomavirus (HPV) is the most common viral infection of the reproductive tract globally and most sexually active women and men will be infected at some point in their lives. ${ }^{1}$ Human papillomavirus is sexually transmitted and most infections are usually acquired shortly after becoming
Correspondence to: Prof. A. R. Isara Email: mansaray2001@yahoo.zcom Phone number: 08034057565 sexually active. Human papillomavirus infection is well recognized as the cause of nearly all cases of cervical cancer but infection with certain types of HPV also causes a proportion of cancers of the anus, vulva, vagina, penis and head and neck oropharynx. ${ }^{1}$ Human papillomavirus is also 
responsible for an important fraction of head and neck cancer. ${ }^{2}$

More than 100 serotypes of HPV exist, and are classified as low risk and high risk. Thirty of these target the genitalia and approximately 15 types are cancer-causing (high risk HPV). It is estimated that about three out of four people have HPV at some point in their lives and by the age of 50 years, at least 80 percent of women will have acquired the HPV infection. ${ }^{1,3,4}$ Persistent infection with high-risk HPV subtypes 16 and 18 have been established to be responsible for about $70 \%$ of all cervical cancer cases worldwide. ${ }^{5}$ Human papillomavirus infection is most prevalent in the younger population with the highest rate in the age range of 20 to 30 years which include many undergraduate university students.6,7 About 23.7\% of women and $73 \%$ of men in the general population in Nigeria carry an HPV genital infection and within the first three years of sexual debut, $50 \%$ of women have evidence of an HPV infection. ${ }^{5}$

Cervical cancer is ranked as the fourth most frequently diagnosed cancer and the fourth leading cause of cancer death in women with an estimated 570,000 cases and 311,000 deaths in 2018 worldwide. ${ }^{8}$ It is the second most common cancer in women living in less developed regions of the world. ${ }^{1}$ The development of cervical cancer is a multi-stage process that occurs over many years and begins when a woman gets infected with an oncogenic type of the HPV. In Nigeria, cervical cancer ranks as the second most common cancer in women aged
15 to 44 years with about 14,943 new cases diagnosed annually. ${ }^{5}$ It is the second leading cause of cancer mortality in the country. ${ }^{9}$ These statistics are indicative of a very high burden of disease in a country where the population at risk for cervical cancer (females aged 15 years and above) is estimated to be 53.1 million. ${ }^{5}$

Cervical cancer can be prevented through the use of specific interventions such as health education (on delayed sexual debut, practice of safe sex, benefits of HPV vaccination) and prophylactic vaccination against HPV. It can be completely cured when diagnosed early after the use of screening methods such as Papanicolaou (Pap) smear test. Unfortunately, the uptake of both HPV vaccination and cervical screening services are still rudimentary in Nigeria. ${ }^{10}$ It is recommended that girls aged 9 to 15 years should be given a two-dose regime schedule of HPV vaccine with a 6-month interval between the doses $(0,6$ months) before they become sexually active while women aged 16 to 26 years can be given a 3 -dose regime $(0,1$, and 6 months or 0,2 , and 6 months), with cervical cancer screening still necessary after HPV vaccination. ${ }^{2}$ With the HPV vaccination already available as the primary preventive method against cervical cancer one expects a decline in HPV infections. However, despite the strides made in HPV vaccination and education, over half a million women worldwide develop cervical cancer each year and over $85 \%$ of these cases occur in developing countries due to the lack of 
effective screening and prevention programmes. ${ }^{10}$

The launch of HPV vaccine in Nigeria was done in 2009, yet more than a decade after, the knowledge of HPV as the causative agent of cervical and HPV vaccination as a preventive measure against cervical cancer including the uptake of vaccination by the target population of young people is still abysmally low. Many studies carried out among female students in secondary schools and universities in Nigeria have alluded to this fact. ${ }^{11-15}$ In a similar way, parents and caregivers of young people have demonstrated poor knowledge of cervical cancer prevention and screening for their children in Nigeria. ${ }^{16,17}$ The deficiency of such knowledge may adversely affect the acceptability and uptake of HPV vaccine. In addition, the availability and affordability of HPV vaccines is also inimical to the uptake HPV vaccine. Presently in Nigeria, HPV vaccines are only available in private health facilities and at a cost many Nigerians cannot afford. ${ }^{18}$ Efforts that are however being made by the Nigerian government to include the HPV vaccine as part of national routine immunization is rather slow.

University undergraduate students are a special population at risk of cervical cancer. Apart from the fact that most of them are adolescents, some of them may be living independently for the first time. This so called freedom may expose them to indulge in activities which include but not limited to sexual exposures that is capable of predisposing them to HPV infection and cervical cancer in future, especially if they have not been vaccinated against HPV infection. Therefore, to promote the awareness and knowledge of HPV infection and HPV vaccination among university students and to add to the body of evidence of efforts towards reducing the burden of cervical cancer in Nigeria, this study was carried out to assess the knowledge of human papilloma virus and uptake of HPV vaccine among female undergraduate students of Ambrose Alli University, Ekpoma, Nigeria.

\section{METHODOLOGY}

\section{Study area}

The study was carried out at the Ambrose Ali University Ekpoma, Edo State, Nigeria in December 2017. The university was founded in 1981 and was known as Bendel State University (BENSU). It became known as Edo State University (EDSU) upon the creation of Edo and Delta States from the defunct Bendel State in 1991, and then renamed again as Ambrose Alli University in 1999 after the founder and former Governor of the defunct Bendel State, Professor Ambrose Folorunsho Alli. The university has 12 faculties offering undergraduate and postgraduate programmes to full time and part time students. As at the time of the study, there were 15,786 female students in the university.

\section{Study design and population}

This institution-based descriptive crosssectional study was conducted among full time female undergraduate students of the university. Postgraduate and part time 
undergraduate students were excluded from the study.

\section{Sample size calculation and sampling}

The minimum sample size required for the study which was calculated using the formula for single proportions $\left(\mathrm{n}=\mathrm{z}^{2} \mathrm{pq} / \mathrm{d}^{2}\right)$ in a cross-sectional study. ${ }^{19}$ The following assumptions were made at $95 \%$ confidence interval: the estimate of the expected proportion ( $\mathrm{p}$ ) of $14.4 \%$ being the proportion of female students who were aware of HPV vaccine in the University of Lagos, Nigeria, 15 and a desired level of absolute precision $(d)$ of $\pm 5 \%$. Thus the final sample size calculated for this study was 212 .

A multi-staged sampling technique was used to recruit the participants for the study as follows: In the first stage, one department in each of the 12 faculties was selected by simple random sampling technique. The selected departments were: Agricultural Economics, History and International Studies, Medical Laboratory Science, Medicine, Vocational and Technical Education, Fine and Applied Arts, Chemical Engineering, Botany, Law, Business Administration, Chemistry, and Library and Information Science. In stage two, a simple random sampling technique was used to select one academic level of study in each of the selected departments. In the third stage, participants were recruited from each level using a systematic random sampling technique. The class list for the particular level in the selected department obtained from the Head of Department was used as the sampling frame and the sampling interval (k) was calculated using the following formulae, $k=\frac{N}{n}$ where $\mathrm{k}$ is the sampling interval, $\mathrm{N}$ is the population of female students in the department, and $\mathrm{n}$ is the number of study participants allocated to the faculty. The first study participant was selected by simple random sampling within the sampling interval for that faculty and subsequently every $\mathrm{k}^{\text {th }}$ student on the list was recruited until the size allocated to that faculty is reached. A proportional allocation according to the total number of female students in the respective faculties was done to determine the number of students that participated in each faculty.

\section{Data collection and analysis}

A structured, pretested, self-administered questionnaire was the tool for data collection in this study. The questionnaire contained questions on the sociodemographic profile of the students, their knowledge of HPV, awareness of the existence of HPV vaccine and the uptake of HPV vaccine.

Data collected were screened for completeness, coded and analyzed using IBM SPSS version 21.0 (IBM Corp, Armonk, NY, USA). An initial univariate analysis was carried out to assess the distribution of the variables. Sexual activity in this study was taken as prior exposure to a penetrative sexual intercourse. This is because one singular act of penetrative sexual intercourse is enough to contract HPV infection. Uptake of HPV vaccination was defined as having received at least one dose of HPV vaccine. 
Chi-square statistical tests was used to test the association between the sociodemographic characteristics of the students and their knowledge of HPV. A composite scoring was done for the purpose of the bivariate analysis. Knowledge of HPV was assessed using ten questions which covers the folowing areas: awareness of HPV infection, mode of transmission of HPV, whether HPV can cause cervical cancer and how HPV infection can be prevented. A correct answer to each question was given a score of "1" while an incorrect answer was scored zero. The total score was converted to percentage and classified thus: poor level of knowledge was a score of less than $50.0 \%$, and good level of knowledge was a score of $50.0 \%$ and above. A $\mathrm{p}$ value less than 0.05 was considered as statistically significant.

\section{Ethical consideration}

Ethical approval for the study was obtained from the Health Research Ethics Committee, Ambrose Alli University (Protocol number 009/17). The management of Ambrose Alli University also gave permission for the study. Verbal informed consent was also obtained from the students after full assurance of confidentiallity before data collection.

\section{RESULTS}

A total of 229 female undergraduate students participated in the study. Their ages ranged from 16 to 32 years with a mean age of $21 \pm 2.5$ years. Most of the students $223(97.4 \%)$ were Christians and almost all of them 228 (99.6\%) were single. A higher proportion of them 139 (60.7\%) were in 400 level of study, followed by 72 (31.4\%) in 200 level while $18(7.9 \%)$ were in 300 level. Over two thirds of both parents of the students had tertiary level of education (Table 1).

Table 2 shows the prevalence of risk factors for HPV infection among the students. About one third (32.3\%) were sexually active. Among the sexually active students, slightly more than half $(52.7 \%)$ had their sexual debut at 15 to 19 years of age. Eight (10.8\%) and 27 (36.5\%) had their sexual debut at 10 to 14 years and 20 years and above respectively. The mean age at coitache was $18.5 \pm 3.0$ years while the modal age at coitache was 18.0 years. Twothirds of the students $(67.6 \%)$ reported having only one sexual partner while 9 $(12.1 \%)$ had more than five sexual partners. On the use of condom during sexual intercourse, a higher proportion 32 (43.2\%) reported occasional use while 21 (23.4\%) never used condom during sexual intercourse.

The different domains of knowledge of HPV infection is shown in Table 3. Less than half $(47.6 \%)$ of the students had heard of HPV infection. One hundred and three (45.0\%) and 101 (44.1\%) knew that HPV was a viral infection and is sexually transmitted, respectively. Only 81 (35.4\%) knew that HPV can cause cervical cancer while 84 (36.7\%) affirmed that HPV infection can be prevented by vaccination. The overall composite score of the knowledge of HPV showed that only $34(14.8 \%)$ had good knowledge of HPV infection. 
1: Socio-demographic characteristics of respondents

\begin{tabular}{|c|c|c|}
\hline Variables & $\begin{array}{l}\text { Frequency }(\mathrm{n}= \\
\text { 229) }\end{array}$ & Percent \\
\hline \multicolumn{3}{|l|}{ Age (years) } \\
\hline $16-19$ & 49 & 21.4 \\
\hline $20-24$ & 159 & 69.4 \\
\hline $25-29$ & 18 & 7.9 \\
\hline $30-32$ & 3 & 1.3 \\
\hline \multicolumn{3}{|l|}{$\begin{array}{l}\text { Mean age }=21 \pm \\
2.5 \text { years. }\end{array}$} \\
\hline \multicolumn{3}{|l|}{ Religion } \\
\hline Christianity & 223 & 97.4 \\
\hline Islam & 5 & 2.2 \\
\hline $\begin{array}{l}\text { African traditional } \\
\text { religion }\end{array}$ & 1 & 0.4 \\
\hline \multicolumn{3}{|l|}{ Marital status } \\
\hline Single & 228 & 99.6 \\
\hline Married & 1 & 0.4 \\
\hline \multicolumn{3}{|l|}{ Level } \\
\hline 200 & 72 & 31.4 \\
\hline 300 & 18 & 7.9 \\
\hline 400 & 139 & 60.7 \\
\hline \multicolumn{3}{|l|}{$\begin{array}{l}\text { Father's level of } \\
\text { education }\end{array}$} \\
\hline Primary & 7 & 3.1 \\
\hline Secondary & 47 & 20.5 \\
\hline Tertiary & 175 & 76.4 \\
\hline \multicolumn{3}{|l|}{$\begin{array}{l}\text { Mother's level of } \\
\text { education }\end{array}$} \\
\hline Primary & 23 & 10.0 \\
\hline Secondary & 53 & 23.1 \\
\hline Tertiary & 153 & 66.8 \\
\hline
\end{tabular}

Age range - 16 to 32 years

Table 4 showed the association between the socio-demographic characteristics of the students and their knowledge of HPV. There was an increase in knowledge of HPV with increasing age and increasing level of study. This association was statistically significant, $\mathrm{p}=0.031$ and $\mathrm{p}=0.026$, respectively. Although, the students whose parents had tertiary level of education were more knowledgeable about HPV, the association between the parents' level of education and the students' knowledge of HPV was not statistically significant.

When asked of their awareness of HPV vaccines, only $39(17.0 \%)$ of the students affirmed that they were aware of the existence of HPV vaccines. Majority of the students 190 (83.0\%) were not aware that there is a vaccine against HPV infection. Among those who were aware of HPV vaccines, the major sources of information about HPV vaccines as stated by the students were health care workers $(41.0 \%)$, friends $(23.1 \%)$ and social media/internet $(23.1 \%)$. Only 1 (2.6\%) student got information from a sibling. Overall, only one student $(0.4 \%)$ reported to have received the HPV vaccine prior to the study (Table 5).

\section{DISCUSSION}

It is no accident that HPV infection, and by implication cervical cancer, both of which are preventable, still continuously dominates as leading cause of morbidity and mortality in many sub-Saharan countries including Nigeria. This study demonstrated a very poor knowledge of HPV infection as a cause of cervical cancer and a near zero uptake of HPV vaccine among the female undergraduate students studied. This finding in a tertiary institution among young literate women in the prime of their lives is an indication that the situation may be worse in the general population considering the high number of young women who do not have the opportunity to attain tertiary level of education in Nigeria. In this study, only $14.8 \%$ of the students were knowledgeable about HPV being the cause of cervical cancer. This poor knowledge is comparable to the $11.1 \%$ reported in a study among university students in Lagos, Nigeria ${ }^{15}$ and in others countries of the world like Ghana (7.9\%),20 
Table 2: Risk factors for HPV infection among the respondents

\begin{tabular}{|c|c|c|}
\hline Variable & Frequency & Percent \\
\hline \multicolumn{3}{|c|}{ Sexual activity (n = 229) } \\
\hline Yes & 74 & 32.3 \\
\hline No & 155 & 67.7 \\
\hline \multicolumn{3}{|c|}{ Age at coitache in years ${ }^{*}(n=74)$} \\
\hline $10-14$ & 8 & 10.8 \\
\hline $15-19$ & 39 & 52.7 \\
\hline$\geq 20$ & 27 & 36.5 \\
\hline \multicolumn{3}{|c|}{ Number of sexual partners $(n=74)$} \\
\hline 1 & 50 & 67.6 \\
\hline $2-5$ & 15 & 20.3 \\
\hline$>5$ & 9 & 12.1 \\
\hline \multicolumn{3}{|c|}{ Use of condom $(n=74)$} \\
\hline Always & 21 & 28.4 \\
\hline Sometimes & 32 & 43.2 \\
\hline Never & 21 & 28.4 \\
\hline
\end{tabular}

Table 3: Knowledge of HPV infection among respondents

\begin{tabular}{lrl}
\hline Variable & Frequency (n = 229) & Percent \\
\hline Have heard of HPV infection & 109 & 47.6 \\
HPV is a viral infection & 103 & 45.0 \\
HPV is a sexually transmitted infection & 101 & 44.1 \\
Multiple sexual partners predispose to HPV infection & 87 & 38.0 \\
Weak immune system predisposes to HPV infection & 25 & 10.9 \\
HPV can cause cervical cancer & 81 & 35.4 \\
HPV can cause genital warts & 58 & 25.3 \\
HPV infection can cause penile cancer & 37 & 16.2 \\
HPV infection can be prevented by vaccination & 84 & 36.7 \\
HPV infection can be prevented by use of condom & 50 & 21.8 \\
\hline
\end{tabular}

Table 4: Respondents' socio-demographic characteristics and knowledge of HPV infection

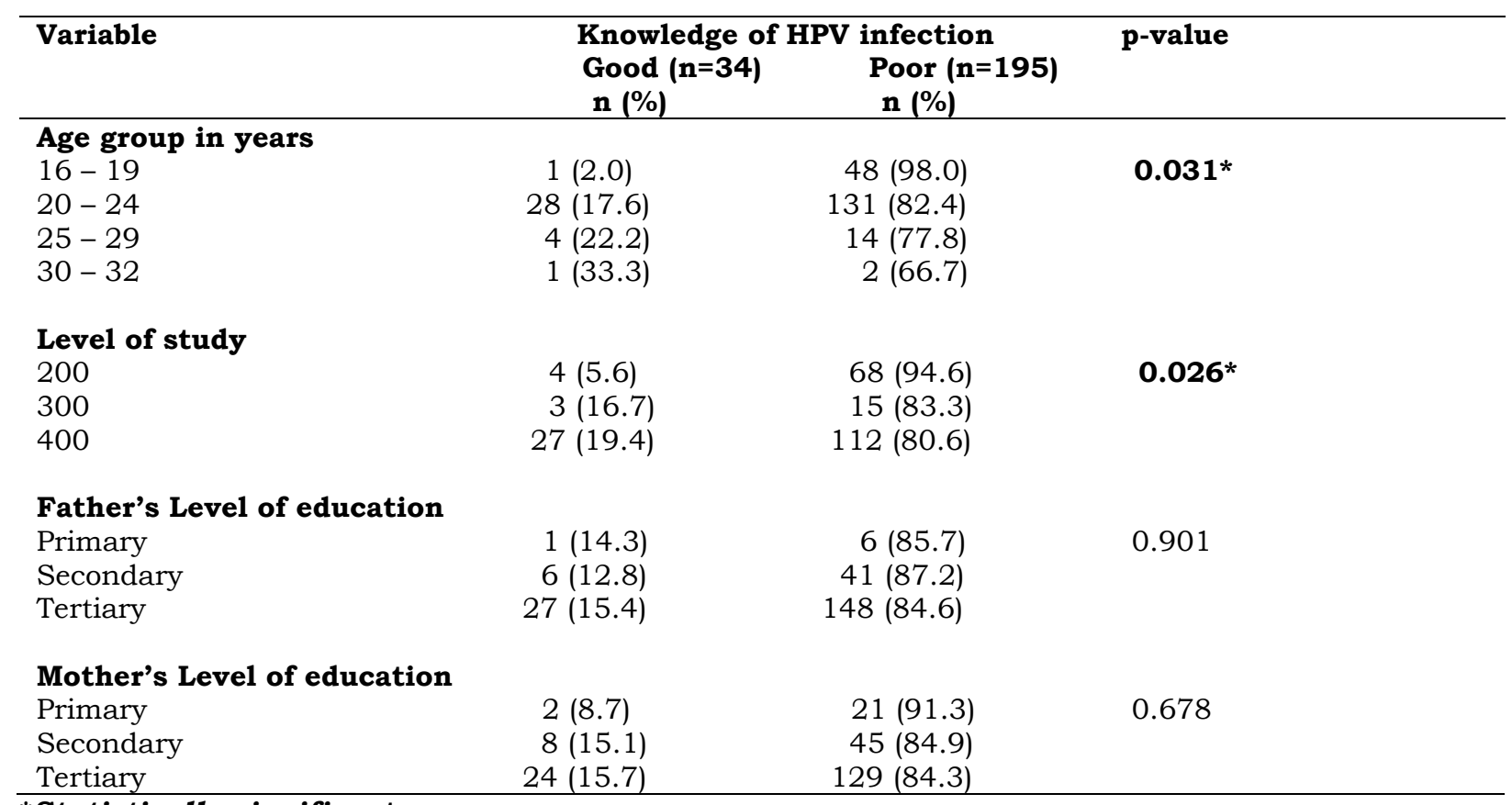

\footnotetext{
*Statistically significant
} 
Table 5: Awareness, major source of information and uptake of HPV vaccine

\begin{tabular}{llr}
\hline Knowledge & Frequency & Percent \\
\hline Awareness (n = 229) & 39 & 17.0 \\
Yes & 190 & 83.0 \\
No & & \\
Source of information (n = 39) & 16 & 41.0 \\
Healthcare workers & 9 & 23.1 \\
Friends & 9 & 23.1 \\
Social media/Internet & 2 & 5.1 \\
Television/Radio & 2 & 5.1 \\
Books & 1 & 2.6 \\
Siblings & & \\
Uptake (n = 229) & 1 & 0.4 \\
Yes & 228 & 99.6 \\
No & & \\
\hline
\end{tabular}

India $(15.0 \%),{ }^{21}$ and in a systematic review carried out in sub-Saharan African countries. ${ }^{22}$ However, a study in Pakistan reported that $55 \%$ of university students knew that HPV causes cervical cancer. ${ }^{23}$

Poor knowledge of HPV infection exhibited by young female undergraduate students is definitely a potential set back that can jeopardize HPV infection and cervical cancer prevention control efforts in any population. Increasing age and level of study of the students were significantly associated with knowledge of HPV infections. The Lagos study also reported an association between a higher level of study and knowledge of HPV. ${ }^{15}$ This finding is quite understandable because of the positive correlation between age and the level of study of students. Older students in higher levels of study would have been more exposed to various sources of information on HPV in the course of their study. The high level of education of the parents of the students in this study did not show any significant association with the knowledge of HPV. This is not surprising because studies have shown that many parents and caregivers also exhibit poor knowledge of HPV and cervical cancer, 13, 17, 24-26 and so they may not be in the position to pass information to their children. This is a demonstration of the maxim that "you cannot give what you do not have". But the good aspect of this finding is that, it underscores the need for activities aimed at promoting awareness of HPV and cervical cancer to be all-inclusive in terms of its target i.e. children, adolescents, young people and adult males and females.

The awareness of the existence of HPV vaccines was very poor among the students in this study and this also dovetail into the near zero uptake of the vaccine by the students. Lack of awareness of HPV vaccine will impact negatively on the uptake of the vaccine. It is not surprising that none of the students mentioned their parents as their source of information about HPV vaccines. This finding underscores the need for parents to be educated on their role in the fight against HPV infection and cervical cancer. Low uptake of HPV vaccines among students have also been reported in 
previous studies in Nigeria such as Lagos $(2.6 \%),{ }^{11}$ Benin City $(3.7 \%),{ }^{27}$ Ibadan (4.1\%), 14 Port Harcourt (5.1\%),12 Enugu $(6.9 \%),{ }^{17}$ and in Lebanon $(2.5 \%)^{28}$ and Malaysia (3.6\%). ${ }^{29}$ In contrast, a much higher uptake was reported in developed countries like the United States of America $(47.3 \%)^{30}$ and Germany $(67.0 \%) .31$ Other factors that militate against HPV vaccine uptake in Nigeria as has been documented in previous reports include cost and availability of vaccines. ${ }^{17,18,32}$

It is sad to note that more than a decade after the launch of HPV vaccine in Nigeria, it is yet to be made readily available to the populace at a cost that they can afford. An intensive health promotion programme to raise awareness about the existence of HPV vaccines and its uptake coupled with readily available HPV vaccines will go a long way in the prevention of HPV infection and cervical cancer in Nigeria. A study in northern Nigeria revealed that more than $70 \%$ of female undergraduate students expressed willingness to accept HPV vaccine. ${ }^{33}$ Also, majority of mothers and caregivers in Nigeria were willing to have their daughters vaccinated against HPV infection. ${ }^{15,17}$ This positive disposition expressed by both female students and mothers/caregivers is quite encouraging and it can be utilized to improve HPV vaccine uptake in the target population.

Some risk factors for HPV infection were identified in this study. Among those who were sexually active, $10.8 \%$ had their first sexual intercourse between the ages of 10 and 14 years. This early sexual exposure has serious implications for HPV infection especially when about one quarter of the students reported that they never used condom during sexual intercourse. Early exposure to unprotected sexual intercourse and multiple sexual partners are major determinants of HPV infection. Thus, there is need for female children to be educated early in life (in primary schools) about risk factors for HPV infections and cervical cancer and this should culminate in their reception of HPV vaccine before they enter secondary school. Another worrisome risk of HPV infection among young female children in Nigeria is the rising incidence of sexual assault. This was corroborated by the recent United Nations report that there is a $56 \%$ rise in gender based violence in Nigeria with some of these incidents of violence tragically resulting in the rape of children, including incestual rape. ${ }^{34}$ Apart from the immediate physical and psychological trauma faced by female children who are victims of rape, they are also exposed to various sexually transmitted infections such as human immunodeficiency virus (HIV), hepatitis B, hepatitis $\mathrm{C}$ and HPV infections. The infection with HPV will lead to long term complication of cervical cancer. Therefore, all hands must be on deck in the use of preventative measure such as awareness promotion and scaled HPV vaccination to save female children in particular and the entire country in general from the menace and burden of HPV infections and cervical cancer. The use of a self-administered questionnaire without identifiers was 
adopted to enable the students expressed themselves freely without reservation because of the sensitive nature of issues of sexual and reproductive health in the African setting. However, the study may have been prone to both information and recall biases.

Conclusion: This study showed that the knowledge of HPV infection as a cause of cervical cancer was very poor among the female undergraduate students studied. Despite the considerable proportion of students who may be at risk of HPV infection, there was an abysmally low uptake of HPV vaccination by the students.

Education on HPV infection and cervical cancer should be promoted in all primary, secondary and tertiary institutions in the country to increase awareness and to serve as reinforcement for increased knowledge of HPV infection and cervical cancer. Parents and caregivers should make conscious effort to ensure their children receive HPV vaccination before they become sexually active. Young girls should be made to show evidence of HPV vaccination before they are admitted into secondary schools.

The Federal Government of Nigeria through the Federal Ministry of Health and the National Primary Health Care Development Agency should take urgent steps to incorporate HPV vaccine into the routine immunization schedule of the country in line with the WHO recommendation, so that young girls can be immunized against HPV infection for free. At worst, government should highly subsidize the HPV vaccine to drastically reduce the cost so that it is conveniently affordable to the huge population of low and no-income earners in the country. This will help to reduce the huge health resource that would have been expended on treatment of cervical cancer and its complications.

Conflict of interest: The authors declare no conflict of interest.

Authors' Contribution: All authors contributed to the conceptualization, design, data collection, data analysis /interpretation and preparation of the manuscript.

\section{REFERENCES}

1. World Health Organization. Fact sheet on human papillomavirus (HPV) and cervical cancer. 2019. [cited July 3, 2020]. Available from:

https://www.who.int/news-room/factsheets/detail/human-papillomavirus(hpv)-and-cervical-cancer.

2. Akinola OI, Aimakhu CO, Ezechi OC, Fasubaa OB. Society of Obstetrics and Gynecology of Nigeria - Clinical practice guidelines: Guidelines for the prevention of cervical cancer. Trop J Obstet Gynaecol 2018; 35: 371-376.

3. Kiprono J, Awuoche E, SugeTitus K, Wilda sO, Onyambu E, Jeridah M. Knowledge, attitude and practices of students enrolled in health-related courses at Saint Louis University towards Human Papillomavirus (Philippines). Journal of Natural Sciences Research. 2012; 2: 1-7.

4. Center for Disease Control and Prevention. Human papillomavirus (HPV) infection. [cited August 20, 2020] Available at http://www.cdc.gov/std/HPV/default.ht $\underline{\mathrm{m}}$.

5. Bruni L, Albero G, Serrano B, Mena M, Gómez D, Muñoz J et al. ICO/IARC Information Centre on HPV and Cancer (HPV Information Centre). Human Papillomavirus and related diseases in Nigeria. Summary Report 17 June 2019. [cited July 3, 2020]. Available from: 
https://www.hpvcentre.net/statistics/rep orts/XWX.pdf.

6. Songthap A, Pitisuttithum P, Kaewkungwal J, Fungladda W, Bussaratid $\mathrm{V}$, Koonsaeng S. Knowledge, attitude and acceptability of a human papillomavirus vaccine among healthcare providers. Southeast Asian J Trop Med Public Health. 2009; 40(5): 1048-1056.

7. Izekor $\mathrm{S}$, Osifo $\mathrm{U}$, Orhue $\mathrm{P}$, Momoh $\mathrm{A}$, Airhomwanbo K. Knowledge and practice of condom usage among undergraduate students in Edo State, Nigeria. International Journal of Community Research. 2014; 3(1): 12-18.

8. Bray F, Ferlay J, Soerjomataram I, Siegel RL, Torre LA, Jemal A. Global Cancer Statistics 2018: GLOBOCAN estimates of incidence and mortality worldwide for 36 cancers in 185 countries. CA Cancer J Clin. 2018; 68: 394-424.

9. World Health Organization. Nigeria's call to action - Time to Eliminate Cervical Cancer in Nigeria. 2020. [cited August 20, 2020]. Available from: Available from: https://www.afro.who.int/news/nigeriascall-action-time-eliminate-cervical-cancernigeria.

10. Ferlay J, Shin H, Bray F, Forman D, Mathers C, Parkin D. Estimates of worldwide burden of cancer in 2008. Int $\mathrm{J}$ Cancer Prevention. 2010; 127: 2893-2917.

11. Oluwole EO, Idowu OM, Adejimi AA, Balogun MR, Osanyin GE. Knowledge, attitude and uptake of human papillomavirus vaccination among female undergraduates in Lagos State, Nigeria. J Family Med Prim Care. 2019; 8(11): 36273633.

12. Ojimah C, Maduka O. Awareness and uptake of human papillomavirus vaccines among female undergraduate students: Implications for cervical cancer prevention in South-South, Nigeria. Port Harcourt Med J. 2017; 11: 134-140.

13. Bisi-Onyemaechi AI, Ugo N. Chikani UN, Nduagubam O. Reducing incidence of cervical cancer: knowledge and attitudes of caregivers in a Nigerian city to human papillomavirus vaccination. Infectious Agents and Cancer. 2018; 13: 29.

14. Ndikom CM, Oboh PI. Perception, acceptance and uptake of human papillomavirus vaccine among female adolescents in selected secondary schools in Ibadan, Nigeria. Afr. J. Biomed. Res. 2017; 20: 237-244.

15. Makwe CC, Anorlu RI, Odeyemi KA. Human papillomavirus (HPV) infection and vaccines: Knowledge, attitude and perception among female students at the University of Lagos, Lagos, Nigeria. Journal of Epidemiology and Global Health. 2012; 2: 199-206.

16. Ifedioha $\mathrm{CO}$, Azuike AC. Knowledge and attitudes about cervical cancer and its prevention among female secondary school students in Nigeria. Trop Med Int Health. 2018; 23(7): 714-723.

17. Azuogu BN, Umeokonkwo CD, Azuogu VC, Onwe OE, Okedo-Alex IN, Egbuji CC. Appraisal of willingness to vaccinate daughters with human papillomavirus vaccine and cervical cancer screening uptake among mothers of adolescent students in Abakaliki, Nigeria. Niger J Clin Pract 2019; 22: 1286-1291.

18. Igomu T, Folorunsho-Francis A. HPV vaccine, the cervical cancer prevention most Nigerian women don't know. Punch Newspapers. [cited February 9, 2020]. Available at:

https://healthwise.punchng.com/hpvvaccine-the-cervical-cancer-preventionmost-nigerian-women-dont-know/.

19. Cochran WG. 1963. Sampling Techniques, 2nd Ed., New York: John Wiley and Sons, Inc.

20. Abotchie PN, Shokar NK. Cervical cancer screening among college students in Ghana: Knowledge and health beliefs. Int $\mathrm{J}$ Gynecol Cancer. 2009; 19(3): 412-416.

21. Hussain S, Nasare V, Kumari M, Sharma $\mathrm{S}$, Khan MA, Das BC et al. Perception of human papillomavirus infection, cervical cancer and HPV vaccination in North Indian population. PLoS ONE. 2014; 9(11): e112861.

22. Khan TM, Buksh MA, Rehman IU, Saleem A. Knowledge, attitudes, and perception towards human papillomavirus among university students in Pakistan. Papillomavirus Research. 2016; 2: 122127.

23. Perlman S, Wamai RG, Bain PA, Welty T, Welty E, Ogembo JG. Knowledge and awareness of HPV vaccine and acceptability to vaccinate in Sub-Saharan 
Africa: A systematic review. PLoS ONE. 2014; 9(3): e90912.

24. Abiodun OA, Fatungase OK, Olu-Abiodun OO, Idowu-Ajiboye BA, Awosile JO. An assessment of women's awareness and knowledge about cervical cancer and screening and the barriers to cervical screening in Ogun State, Nigeria. Journal of Dental and Medical Sciences. 2013; 10(3): 52-58.

25. Sopian MM, Shaaban J, Yusoff SSM, Mohamad WMZW. Knowledge, decisionmaking and acceptance of human papillomavirus vaccination among parents of primary school students in Kota Bharu, Kelantan, Malaysia. Asian Pac J Cancer Prev. 2018; 19(6): 1509-1514.

26. Wong LP, Wong YL, Low WY, Khoo EM, Shuib R. Knowledge and awareness of cervical cancer and screening among Malaysian women who have never had a Pap smear: a qualitative study. Singapore Med J. 2009; 50(1): 49-53.

27. Onowhakpor AO, Omuemu VO, Osagie OL, Odili CG. Human papillomavirus vaccination: Knowledge, attitude and uptake among female medical and dental students in a tertiary institution in BeninCity, Nigeria. Journal of Community Medicine and Primary Health Care. 2015; 28(2): 101-108.

28. El-Ola MJA, Rajab MA, Abdallah DI, Fawaz IA, Awad LS, Tamin HM et al. Low rate of human papillomavirus vaccination among schoolgirls in Lebanon: barriers to vaccination with a focus on mothers' knowledge about available vaccines. Therapeutics and Clinical Risk Management. 2018; 14: 617-626.

29. Rashwan HH, Saat NZ, Abd Manan DN. Knowledge, attitude and practice of Malaysian medical and pharmacy students towards human papillomavirus vaccination. Asian Pacific Journal of Cancer Prevention. 2012; 13(5): 22792283.

30. Barnard M, George P, Perryman ML, Wolff LA. Human papillomavirus (HPV) vaccine knowledge, attitudes, and uptake in college students: Implications from the Precaution Adoption Process Model. PLoS ONE. 2017; 12(8): e0182266.

31. Blödt S, Holmberg C, Müller-Nordhorn J, Rieckmann N. Human papillomavirus awareness, knowledge and vaccine acceptance: A survey among 18-25 years old male and female vocational school students in Berlin, Germany. European Journal of Public Health. 2011; 22(6): 808813.

32. Adejuyigbe FF, Balogun MR, Sekoni AO, Adegbola AA. Cervical cancer and human papillomavirus knowledge and acceptance of vaccination among medical students in southwest Nigeria. Afr J Reprod Health. 2015; 19(1): 140-148.

33. Iliyasu Z, Abubakar IS, Aliyu $\mathrm{MH}$, Galadanci HS. Cervical cancer risk perception and predictors of human papillomavirus vaccine acceptance among female university students in northern Nigeria. J Obstet Gynaecol. 2010; 30(8): 857-862.

34. United Nations Nigeria. Gender-based violence in Nigeria during the Covid-19 crisis: The shadow pandemic. 2020. [cited September 3, 2020]. Available from: https: / / nigeria.un.org/sites / default/files /202005/GenderBasedViolenceinNigeriaD uringCOVID19Crisis_TheShadowPandemi c.pdf. 